\title{
Problemas de adição e subtração nos livros didáticos de matemática dos anos iniciais: uma análise à luz da teoria dos campos conceituais
}

\section{RESUMO}

Fátima Jacinta de Aguiar fatimajaguiar@gmail.com 0000-0002-9848-1775

Universidade Estadual do Paraná Campo Mourão, Paraná, Brasil.

Tiago Pereira tiago025pereira@hotmail.com 0000-0001-7430-2392

Universidade Estadual Paulista "Júlio de Mesquita Filho", Rio Claro, São Paulo, Brasil.

Victor Hugo Ricco Bone Antunes antunesvictorh@gmail.com 0000-0002-4755-7645 Universidade do Oeste do Paraná Cascavel, Paraná, Brasil.

Veridiana Rezende rezendeveridiana@gmail.com 0000-0002-4158-2196

Universidade Estadual do Paraná Campo Mourão, Paraná, Brasil. Universidade Estadual do Oeste do Paraná, Campo Mourão, Paraná, Brasil.

\begin{abstract}
A teoria dos Campos Conceituais nos proporciona reflexões sobre as estruturas e classes de problemas de adição e subtração, presentes no Campo Conceitual Aditivo. Neste trabalho, visamos investigar e discutir os problemas desse campo conceitual a partir de uma coleção de livros didáticos dos Anos Iniciais. Cada estrutura de problema identificada nos livros foi discutida apresentando seu formato, bem como um exemplo desta presente nos livros analisados, acompanhado de reflexões. Nossas análises contemplaram mil e oitenta e cinco (1085) exercícios dos cinco (05) volumes da coleção Ápis, que nos permitiram chegar a conclusões de cunho quantitativo e qualitativo, dentre as quais destacamos as classes de problemas predominantes em cada livro, os diferentes tipos de problemas presentes nos diferentes volumes conforme avançam os anos escolares.
\end{abstract}

PALAVRAS-CHAVE: Campo conceitual aditivo. Ensino de matemática. Livro didático. 


\section{INTRODUÇÃO}

As operações de adição e subtração são importantes para a formação dos estudantes, bem como para todo cidadão pelo seu inerente aspecto pragmático. A necessidade de efetuar e mobilizar conceitos pertinentes a essas operações na realização de atividades rotineiras é frequente. Sabendo disso, reconhecer a importância das operações de adição e subtração para formação básica do aluno e destinar estudos que permitam compreender e refletir sobre as características próprias desse conteúdo e sobre o seu ensino e aprendizagem faz-se necessário (ANJOS, 2014).

Mediante tal importância, os problemas de adição e subtração estão presentes desde os primeiros anos de escolarização. Mesmo assim, dificuldades em realizar essas operações são constatadas em alunos do Ensino Médio (BATISTA, 1995), e até mesmo em futuros professores dos Anos Iniciais (REZENDE, BORGES, 2015). Superar essas dificuldades faz parte do desafio de ensinar os conceitos de adição e subtração.

Vergnaud (1993) aponta que para dominar um conceito o aluno precisa ser capaz de vivenciar diversos tipos de situações, não bastando saber apenas realizar cálculos numéricos. Essa diversificação de situações está presente nas seis Relações Aditivas de Base: Problemas de Composição, Problemas de Transformação, Problemas de Comparação, Composição de Transformações, Transformação de Composição e Comparação com Composição de Transformação, contempladas em nossas análises, conforme Magina et al. (2008). A diversificação destas estruturas no ensino de Matemática é essencial para que os alunos possam compreender a essência das operações de adição e subtração.

Vergnaud (1996) nos revela que a ausência destes problemas no processo escolar leva cerca de $80 \%$ dos alunos de até 14 anos a não conseguirem resolver um problema que envolva uma operação tão simples como $5+7$, pois mesmo uma operação elementar pode esconder estruturas sofisticadas que exijam, por exemplo, um raciocínio contra-intuitivo, isto é, para solução do problema realizase uma operação inversa da transformação indicada no enunciado. Esse raciocínio pode não ser criado espontaneamente pela criança. Logo, para que ocorra a apropriação dessas ideias é preciso o envolvimento do estudante em situações que necessitem desse pensamento, e é papel do professor propiciar tais situações.

Pensando na importância das Relações Aditivas de Base para o ensino, desenvolvemos essa pesquisa que tem sua essência atrelada aos estudos realizados na disciplina de Didática da Matemática, cursada pelos três primeiros autores deste trabalho e ministrada pela última autora no ano de 2016, numa Universidade pública do Paraná. A referida disciplina tem como propósito estudar fenômenos didáticos que ocorrem no interior das salas de aula da Matemática, e que dizem respeito ao triângulo didático: professor, aluno e saber (BROUSSEAU, 2008). Tais estudos são respaldados em algumas teorias de Didática da Matemática, dentre elas a Teoria dos Campos Conceituais, teoria de desenvolvimento cognitivo que interessa à Didática da Matemática.

Sendo assim, desenvolvemos a presente pesquisa com objetivo principal de investigar e discutir os problemas do Campo Conceitual Aditivo contemplados na coleção de livros didáticos Ápis Alfabetização Matemática e Ápis Matemática, PNLD 2013, destinada ao Ensino Fundamental I. Para embasar essa discussão, 
apresentamos cada uma das estruturas do Campo Conceitual Aditivo, juntamente com exemplos dos livros analisados, seguidos de reflexões subsidiadas especialmente pela obra de Magina et al. (2008), a qual oferece um quadro teórico que permite compreender como os alunos aprendem conceitos matemáticos, referentes às operações de adição e subtração, com base na teoria dos Campos Conceituais.

Respaldamos a importância desse estudo no objeto que estamos analisando, o livro didático, que se trata de um dos materiais influentes na prática pedagógica dos professores (BRASIL, 1998). Segundo Bittar (2017), o livro didático é uma das fontes para compreender algumas dificuldades de aprendizagem enfrentadas pelos alunos, pois é este material que fornece apoio aos professores na preparação e desenvolvimento das aulas, auxiliando nas escolhas matemáticas e didáticas que este irá fazer, sendo um dos principais objetos presente na transposição didática do professor (CHEVALLARD, apud BITTAR, 2017).

Desse modo, e considerando o objetivo principal deste texto, delimitamos nosso problema de pesquisa como: Com que frequência, e em qual ano escolar, os problemas de cada classe do Campo Conceitual Aditivo são abordados nas obras analisadas? Para responder esta questão, buscamos evidenciar tanto aspectos quantitativos (número de problemas de cada estrutura), como aspectos qualitativos (mudanças ocorridas nos problemas de uma mesma estrutura com a elevação do grau de seriação). A seguir descrevemos os procedimentos metodológicos adotados, seguido da discussão teórica e resultados alcançados.

\section{PROCEDIMENTOS METODOLÓGICOS: CAMINHOS PERCORRIDOS PARA A REALIZAÇÃO DA PESQUISA}

Ao se estudar elementos da Teoria dos Campos Conceituais, durante a disciplina de Didática da Matemática, no 20 ano do curso de Licenciatura em Matemática, foi solicitado um trabalho em equipe que consistia na análise de um livro didático do Ensino Fundamental I. Naquele momento o objetivo era classificar os problemas, segundo as estruturas do Campo Conceitual Aditivo. Para isso, fizemos uso do livro do 2o ano, Ápis Alfabetização Matemática de Luiz Roberto Dante.

Motivados por aprofundar nossos estudos sobre a Teoria dos Campos Conceituais e direcionados pelas orientações da professora da disciplina, decidimos ampliar as nossas análises à coleção completa Ápis, composta por cinco (05) volumes, de modo que os três (03) primeiros são intitulados Ápis Alfabetização Matemática e os volumes do quarto ano e quinto ano recebem o título de Ápis Matemática. Essa coleção foi escolhida, pois no momento da pesquisa ela era a mais adotada no país, segundo os dados de venda do PNLD 2010 e 2013 para os Anos Iniciais, sendo assim um material que retrata o que é proposto para o ensino de matemática nas escolas do referido nível de ensino.

As análises foram realizadas pelos três licenciandos (primeiros autores deste artigo) em conjunto. Tomamos por aspectos quantitativos a incidência de cada estrutura aditiva descrita por Vergnaud em cada livro individualmente e na coleção completa, e o uso majoritário de uma estrutura para se ensinar um determinado do aluno, coerência cronológica entre o nível dos exercícios, modificações 
ocorridas em uma mesma estrutura para diferentes níveis de ensino, são vistos, por nós, como dados qualitativos.

A classificação dos problemas foi realizada minuciosamente, tomando como base as estruturas do Campo Conceitual Aditivo, e durou em média quatro (04) meses, interpolando com a análise, diversos estudos da teoria, a fim de construir uma classificação do modo mais fiel possível. Baseados em Vergnaud (1990), consideramos como problema todo exercício do livro que dá significado ao conceito, que são de certa forma, contextualizados, desprezando, portanto, tarefas do tipo: "Calcule 5+7". Ademais, é importante ressaltar que a quantidade de tarefas encontradas nos livros não coincide com o total de problemas que os livros apresentam, isso ocorre porque uma mesma atividade contempla mais de uma tarefa, como nos casos em que uma única questão possui diversas alternativas, sendo assim, os dados numéricos apresentados no Quadro 19 consideram o número de tarefas dos livros. Na análise levamos em conta problemas que, apesar da tarefa não pertencer ao campo aditivo, a resolução após sua modelagem passava por uma soma ou subtração.

Nossos levantamentos qualitativos emergiram especialmente do aprofundamento que obtivemos ao realizar um olhar cuidadoso para cada página de cada livro analisado e, caso existissem Relações Aditivas de Base, classificar cada uma delas dentro de uma das seis (06) categorias estabelecidas por Vergnaud e nomeadas por Magina et al. Por meio desse contato minucioso entre os pesquisadores e o material de análise, foram criando-se categorias intuitivas, frutos da percepção, comparação e ordenação dos aspectos do fenômeno estudado. A seguir, apresentamos uma breve descrição de elementos da Teoria dos Campos Conceituais que foram considerados em nossas análises.

\section{ALGUNS ASPECTOS DA TEORIA DOS CAMPOS CONCEITUAIS COM O OLHAR PARA O CAMPO ADITIVO}

Gérard Vergnaud é psicólogo de formação, e suas pesquisas trazem diversas contribuições para a Didática da Matemática. Para Vergnaud a Psicologia, sozinha, não é suficiente para dar conta da teorização em Educação, e a Didática não pode dispensar as contribuições da Psicologia. Assim, nesta perspectiva nasce a Teoria dos Campos Conceituais, teoria de desenvolvimento cognitivo que busca compreender o desenvolvimento dos conceitos, suas filiações e rupturas, no decorrer da aprendizagem escolar.

A apreensão de um conceito, por mais elementar que esse pareça, envolve diversas situações que devem ser levadas em conta no momento do aprendizado. O conceito de adição, por exemplo, que é um dos primeiros a ser ensinado nos Anos Iniciais do Ensino Fundamental já requer do aluno o domínio do princípio de ordenação, a compreensão de cardinalidade, correspondência biunívoca etc, desta forma é importante que o conceito de adição não se confunda com a definição do que vem a ser a operação de adição.

A respeito disso, Vergnaud apresenta sua teoria, calcada na ideia de que o conhecimento está organizado em campos conceituais, ou seja, não é possível se estudar um conceito isoladamente, mas sim por meio de um campo conceitual, de modo que diferentes conceitos, propriedades, teoremas, símbolos e situações se entrelaçam no estudo de um mesmo conceito. 
A definição de Vergnaud (1983) para campo conceitual é dada como um conjunto de problemas e situações cujo tratamento requer conceitos, procedimentos e representações de diferentes tipos, mas intimamente relacionados. É preciso, portanto, que o ensino se preocupe com as situações relacionadas, de algum modo, a esses conceitos; com esquemas que tornam possíveis operá-los e com as diferentes representações que são mobilizadas nessas situações, que são justamente o que Vergnaud denomina de variáveis que influenciam na formação e no desenvolvimento de um conceito (VERGNAUD, 1990).

Essas variáveis são denotadas por Magina et al. (2008) de (S, I, R), sendo: S um conjunto de situações que tornam o conceito significativo; I um conjunto de invariantes (objetos, propriedades e relações) que podem ser reconhecidos e usados pelo sujeito para analisar e dominar essas situações; $R$ um conjunto de representações simbólicas que podem ser usadas para pontuar e representar esses invariantes e, portanto, representar as situações e os procedimentos para lidar com eles.

Vergnaud atribui muita importância à reflexão nas aprendizagens matemáticas, e tenta compreender, nas ações dos sujeitos, quais destas estão relacionadas a conhecimentos implícitos falsos ou verdadeiros, por ele denominados de invariantes operatórios, classificados em duas categorias: teoremas em ação e conceitos em ação. Segundo Vergnaud (1990), os teoremas em ação não são verdadeiros teoremas matemáticos, e nem conceitos em ação são conceitos reconhecidos cientificamente. Eles são categorias de pensamento construídas pelos sujeitos na ação e nem sempre são explicitáveis por eles. "Um conceito em ação é um conceito considerado pertinente na ação. Já um teorema em ação é uma proposição tida como verdadeira na ação" (VERGNAUD, 2009, p.23). Um exemplo simples desses invariantes operatórios se dá geralmente quando pedimos a uma criança com cinco anos para contar determinado objeto, presente em dois espaços diferentes, como cadeiras presentes na cozinha (C) e sala de jantar (K), ela o faz da seguinte maneira: primeiramente conta as cadeiras da cozinha, uma, duas, três, e em seguida segue a contagem continuando pelas cadeiras presentes na sala, quatro, cinco, concluindo então que existem ao todo cinco cadeiras em ambos os cômodos, mobilizando o seguinte teorema em ação $C$ $U K=C+K ; C=3 ; K=2 ; C(3)+K(2)=5$, desta forma a criança faz a união e conta 5 , pois ainda não apreendeu o conceito de cardinalidade, que anos mais tarde quando dominado lhe fará resumir a contagem das cadeiras em $3+2=5$, ou seja, $\operatorname{Card}(\mathrm{C} \cup \mathrm{K})=\operatorname{Card}(\mathrm{C})+\operatorname{Card}(\mathrm{K})$, sendo que $\mathrm{C} \cap \mathrm{K}=\varnothing$, teorema matemático que dá conta dessa competência (MAGINA et al., 2008).

As concepções surgem das ações realizadas pelo aluno ao interagir com as situações. Mas a competência está diretamente ligada ao grau de complexidade da situação (MAGINA et al., 2008). Segundo Vergnaud, é por meio das situações que um conceito vai adquirindo sentido para o aluno. São elas que dão sentido ao conceito e torna-o significativo para o aprendiz. No entanto, repetir problemas cujo raciocínio envolvido é sempre o mesmo não levará o aluno à compreensão do conceito, do ponto de vista de Vergnaud (2009). Nesse sentido, surge a importância de o docente trabalhar em sala de aula situações relacionada à mesma operação numérica, mas que exija do aluno raciocínios diversos, por meio de enunciados com contextos diferentes e valores singulares. 
Não é apenas a resolução do problema que interessa, mas o modo pelo qual o aluno o resolve e, principalmente, os invariantes operatórios que mobiliza ao tentar solucionar esse problema (VERGNAUD, 2009). Por meio dos esquemas mobilizados pelos alunos o professor tem a possibilidade de analisar seus conhecimentos explícitos e implícitos, proporcionando a desestabilização dos invariantes operatórios falsos, e momentos de aprendizagens. Esse processo permite aos alunos passarem de um nível de conhecimento para outro mais elaborado.

Segundo Vergnaud (2009), "[...] esquema é uma organização invariante da atividade para uma classe de situações dada". Além disso, é preciso considerar que "[...] cada esquema se relaciona com uma classe de situações com características bem definidas" (VERGNAUD, 1993, p. 5). O pesquisador chama atenção para a existência de duas classes de situações, nas quais o conceito de esquema não funciona do mesmo modo:

1) Classe de situações que o sujeito dispõe em seu repertório, em dado momento de seu desenvolvimento e sob certas circunstâncias, das competências necessárias ao tratamento relativamente imediato da situação.

2) Classe de situações em que o sujeito não dispõe de todas as competências necessárias, o que o obriga a um tempo de reflexão e exploração, a hesitações, a tentativas frustradas, levando-o eventualmente ao sucesso ou ao fracasso (VERGNAUD, 1990, p. 136).

No primeiro caso, observa-se que o sujeito apresenta condutas automatizadas e organizadas por um único esquema. Já no segundo, é possível que o aluno apresente tentativas de vários esquemas que entram em competição, que necessitam serem organizados, descombinados e recombinados. Este último caso é um processo acompanhado necessariamente por descobertas (VERGNAUD, 1990).

Diversos Campos Conceituais têm sido investigados por Vergnaud e colaboradores ao longo das últimas décadas, dentre eles citamos os Campos Conceituais Aditivo, Multiplicativo, Volume, Alfabetização entre outros de diferentes áreas do conhecimento. No entanto, entre os Campos Conceituais estudados, pode-se afirmar que o campo das Relações Aditivas de Base, assim como o das estruturas multiplicativas, possui vantagens perante aos demais campos já estudados, pois "[...] a classificação das relações elementares e das classes de problemas elementares é, neste campo, relativamente avançada e reconhecida na comunidade de pesquisadores" (VERGNAUD, 1993, p.17). A classificação dos problemas realizados por Vergnaud resulta em seis classes de problemas bem definidos: Problemas de Composição, Problemas de Transformação, Problemas de Comparação, Composição de Transformações, Transformação de Composição e Comparação com Composição de Transformação. Assim, o conjunto dessas situações que envolvem as operações de adição e/ou subtração, os conceitos, teoremas, propriedades, representações, símbolos é denominado como Campo Conceitual Aditivo. Tais situações contemplam diversos elementos tais como: os conceitos de cardinal, de medida, número natural, número relativo, transformação temporal (perder ou ganhar), composição binária de medidas (quantos são ao todo?), entre outros. 
contar os degraus de uma escada que propiciam às crianças o desenvolvimento de noções matemáticas relativas ao número, à comparação, à adição, à subtração. No entanto, baseados em Vergnaud (1993), os pesquisadores mencionam que a vida propicia poucos casos entre os diferentes problemas possíveis. $E$, para que um aluno compreenda o conceito de adição, não basta mudar o contexto e os números, é preciso que a estrutura dos problemas seja diversificada.

Sendo assim, considerando a importância da diversificação das Relações Aditivas de Base, apresentamos a descrição de cada uma das seis (06) classes de problemas do Campo Conceitual Aditivo, conforme Magina et al. (2008). Buscamos exemplificar cada estrutura com problemas presentes nas obras da coleção analisada. De acordo com nossas análises, algumas classes de problemas estabelecidas tanto por Vergnaud (1983, p. 128) quanto por Magina et al. (2008) não foram identificadas na coleção analisada, portanto, as descrições a seguir referem-se apenas às classes de problemas identificadas nas análises.

Para que possamos entender as Relações Aditivas de Base, utilizamos um quadro que expõem o problema presente nas obras analisadas, o esquema, em que se faz necessário caracterizar as simbologias utilizadas, indicados em Vergnaud (1990, p. 201) e o cálculo numérico para a resolução do problema. Tomemos o quadrado como sendo um número natural que representa as medidas, o círculo indica a relação entre as medidas ou as transformações, ou seja, um número que possui sinal. "Esses números representam adequadamente as transformações aditivas (adições e subtrações) que podem ser aplicadas à medida de um conjunto de objetos isoláveis, acrescentando elementos a este conjunto ou deles os retirando" (VERGNAUD, 2009, p. 199). Cabe ressaltar que as transformações são dinâmicas "pela sua natureza de proporcionar uma mudança de estado, um movimento" (SANTANA, 2012, p. 56) já as relações entre as medidas possuem uma característica estática. Temos também a chave vertical e a flecha curvilínea horizontal que representam a composição de elementos de mesma natureza, já a flecha vertical e a flecha curvilínea horizontal, que se repete, caracterizam uma transformação ou uma relação, ou seja, a composição de elementos de natureza diferente.

Magina et al. (2001) classificou as Relações Aditivas de Base conforme a complexidade das situações. As primeiras ideais de adição e subtração que a criança desenvolve são geradas da própria experiência do seu cotidiano e designadas de protótipos, e é a partir dessas situações que o conceito de adição é iniciado. As demais situações são denominadas por Magina et al. (2001) de extensões, quanto maior o nível de extensão mais difícil são os problemas. Essas concepções serão mais bem compreendidas no decorrer do texto, pois nos atemos a designar para cada estrutura aditiva o seu grau de extensão. É importante listar que a facilidade ou dificuldade dos cálculos envolvidos depende também da ordem como as informações são trazidas, dos tipos de números (natural, inteiro, decimal) e de seus significados (dinheiro, metro, bolinhas de gude, idade) (VERGNAUD, 2009). Informamos que os exemplos de problemas apresentados foram retirados dos livros analisados e contemplam as variações que cada uma das estruturas aditivas apresenta, sendo elas: Problemas de Composição: a variação da incógnita ora encontra-se nas partes, ora no todo; Problemas de Comparação: a alteração na posição da incógnita apresenta-se no valor do referente, referido ou na relação entre as medidas, estando também estas sujeitas a comparações positivas e negativas designadas pelo enunciado do problema e não pela operação; Problemas 
de Transformação: neste caso, a variabilidade da incógnita oscila entre o estado inicial, estado final e na transformação ocorrida, podendo esses três também ser positivos ou negativos, dependendo exclusivamente do contexto do problema.

\section{CLASSES DE PROBLEMAS DO CAMPO ADITIVO IDENTIFICADAS NAS OBRAS ANALISADAS}

No que diz respeito às classes de problemas do Campo Conceitual Aditivo proposto por Magina et al. (2008), a primeira delas se refere aos Problemas de Composição. Nessa estrutura aditiva, as situações problemas envolvem parte e todo. Nos problemas de Composição "busca pelo todo" o contexto é de juntar quantidades, ou seja, uma parte com outra parte para obter o todo. Já nos problemas de Composição "busca pela parte", requer a subtração de uma parte de um todo para obter outra parte.

O problema A, a seguir mostra um exemplo de Composição "busca pelo todo":

Quadro 1: Problema I de Composição.

\begin{tabular}{|c|c|c|c|c|}
\hline Problema A & & Esquema & & Cálculo numérico \\
\hline $\begin{array}{l}\text { Calcule e complete. Na visita ao } \\
\text { museu foram } 9 \text { meninos e } 7 \\
\text { meninas. No total foram } \\
\text { crianças. }\end{array}$ & 7 & \}$_{\text {Parte }}^{\text {Parte }}$ & Todo & $9+7=16$ \\
\hline
\end{tabular}

(Fonte: DANTE (2012, p. 175).)

No problema A, a quantidade de meninos representa uma parte e a quantidade de meninas a outra parte. $\mathrm{O}$ problema questiona sobre o total de crianças, ou seja, a soma das duas partes, que formará o todo das crianças na visita ao museu.

O problema B, trata-se de um problema de Composição "busca pela parte":

Quadro 1: Problema II de Composição.

\begin{tabular}{|l|c|c|}
\hline Problema B & Esquema & Cálculo numérico \\
\hline Na classe de Lúcia há 38 alunos, \\
$\begin{array}{l}\text { e } 21 \text { deles são meninos. O } \\
\text { número de r meninas } \\
\text { é__ }\end{array}$
\end{tabular}

(Fonte: DANTE (2012, p. 221).)

Este problema B apresenta o total de alunos em uma classe, ou seja, o todo, e o número de meninos, que se refere a uma das partes, e questiona a outra parte, o número de meninas. Perceba que no problema de Composição "busca pelo todo" o aluno deve fazer uma adição para encontrar o todo, já no problema de 
Composição "busca pela parte" o aluno deve realizar uma subtração para descobrir a outra parte (todo-parte=parte), esses problemas evocam a ideia de juntar e completar respectivamente.

Problemas desse tipo estão associados ao processo de contagem. Nos estudos feitos por Magina et al. (2008), as autoras classificam os problemas desse formato como protótipo (busca pelo todo) e primeira extensão (busca pela parte), esses são considerados fáceis à maioria das crianças, já que estas não apresentam dificuldade em resolvê-los. Basicamente a ideia central do problema é a de juntar quantidades ou retirar certa quantia de um todo fornecido pelo problema, e é justamente a primeira situação de adição que a criança compreende e que ela forma.

Nossas análises mostram que a complexidade do problema para essa estrutura se refere aos números envolvidos no problema, como mostram os problemas a seguir: números na casa das centenas para o terceiro ano (problema C), e números na casa das centenas de milhão no volume do quarto ano (problema D). Esses problemas, apresentam a mesma estrutura aditiva do problema A (Composição "busca pelo todo") e por isso não apresentamos seus esquemas novamente.

Quadro 2: Problema III de Composição

Problema C: Em uma escola estudam 213 alunos de manhã e 185 à tarde. Qual é o total de alunos nesses dois períodos?

(Fonte: DANTE (2014b, p. 222).)

Quadro 4: Problema IV de Composição.

Problema D: No Censo 2000 foram registrados os seguintes dados no Brasil:

- População urbana: 137953959 habitantes.

- População rural: 31845211 habitantes.

Em seu caderno, use o algoritmo da adição e descubra a população do Brasil registrada no Censo 2000. Escreva também como se lê o número obtido.

(Fonte: DANTE (2013a, p. 125).)

Outra mudança ocorrida quando o nível de seriação aumenta acontece no número de partes do Problema de Composição. Como exemplo disso, apresentamos o problema E proposto no quinto volume da coleção, cujo número de partes é quatro (4) e não mais duas (2) como observado nos volumes anteriores.

Quadro 3: Problema V de Composição.

Problema E: Numa biblioteca há 47 livros de Matemática, 62 de História, 53 de Geografia e 108 de outros assuntos. Qual é o total de livros? Calcule de dois modos diferentes e responda.

(Fonte: DANTE: (2013b, p. 61).)

No que diz respeito ao Problema de Transformação, Magina et al. (2008) apresentam como a classe de problemas que trata de situações em que a ideia temporal está sempre envolvida. Essa estrutura se divide em três (03) componentes: o estado inicial, estado final e a transformação ocorrida.

A estrutura de Transformação cujo estado final é desconhecido é classificada por Magina et al. (2008) como protótipo, nela tem-se a parte inicial que sofre uma transformação que pode ser entendida e caracterizada como um acréscimo, 
decréscimo, ganho ou perda, obtendo-se o estado final. Já a estrutura de Transformação, denominada de primeira extensão, é aquela em que a própria transformação ocorrida é desconhecida pelo aluno, conhecendo-se os estados inicial e final. Por fim, a estrutura de Transformação cujo estado inicial é desconhecido é dita de quarta extensão, e dentre todas é tomada como a mais complexa de se resolver, pois o aluno precisa realizar a operação inversa ao que o enunciado aparenta transmitir. Além disso, outro obstáculo enfrentado pelo aluno na resolução do problema é começar a resolução sem o dado inicial, como usualmente é feito nas demais estruturas.

O problema F trata da estrutura de Transformação "busca pelo estado final".

Quadro 6: Problema I de Transformação.

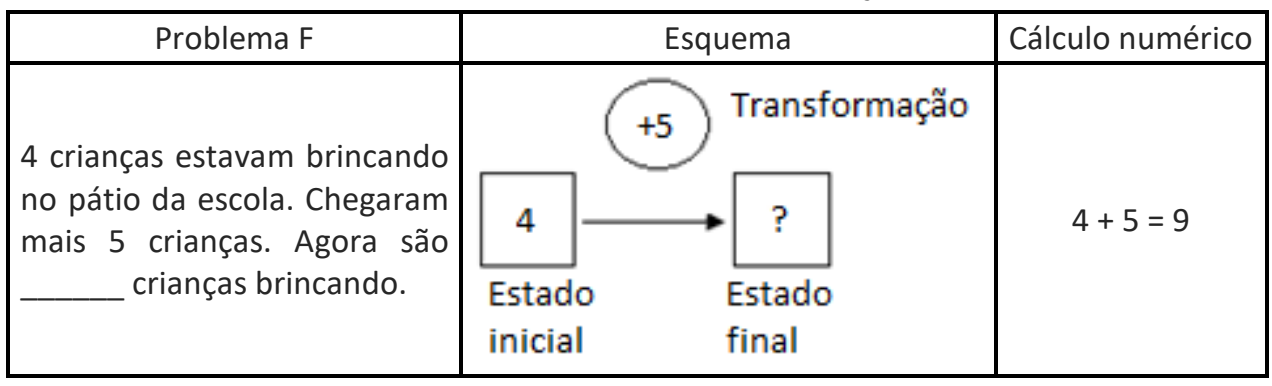

(Fonte: DANTE (2014a, p. 132).)

No problema $\mathrm{F}$ o estado inicial é representado pela quantidade de crianças que brincavam no pátio da escola, ocorre a transformação positiva, a chegada de mais cinco (05) crianças ao pátio. Note que a marca de tempo é evidente no problema ao dizer que "mais" crianças chegaram. Se busca o estado final que é obtido somando-se a quantidade de crianças que já existiam no pátio com as que chegaram. Observe também que a ideia dessa estrutura ocorre em torno do acréscimo, diferente da estrutura de Composição que se baseia na ideia de juntar quantidades e não as modificar, ainda que a operação realizada seja a mesma.

O problema G também se caracteriza como uma estrutura de Transformação "busca pelo estado final", no entanto a transformação é dita negativa.

Quadro 7: Problema II de Transformação.

\begin{tabular}{|c|c|c|c|}
\hline Problema G & \multicolumn{1}{|c|}{ Esquema } & Cálculo numérico \\
\hline $\begin{array}{c}\text { Seu João tinha } 50 \text { balões, } \\
\text { vendeu } 36 \text { balões e ficou com } \\
\text { balões. }\end{array}$ & $\begin{array}{l}\text { Estado } \\
\text { inicial }\end{array}$ & $\begin{array}{l}\text { Estado } \\
\text { final }\end{array}$ & $50-36=14$ \\
\hline
\end{tabular}

(Fonte: DANTE (2014b, p. 93).)

João tinha 50 balões e sofreu uma transformação negativa, pois ele vendeu 36 balões, para que o aluno encontre o valor solicitado, quantos balões João possui após a venda, é necessário efetuar uma subtração, valor inicial menos o valor da transformação. 
Quadro 8: Problema III de Transformação.

\begin{tabular}{|l|l|l|l|}
\hline \multicolumn{2}{|c|}{ Problema $\mathrm{H}$} & \multicolumn{1}{|c|}{ Esquema } & Cálculo numérico \\
\hline $\begin{array}{l}\text { Leia, pense e resolva. } \\
\text { Jairo tinha } \mathrm{R} \$ \text { gastou } \\
\mathrm{R} \$ 147,00 \text { e ficou com } \mathrm{R} \$ \\
219,00 .\end{array}$ & $\begin{array}{l}\text { Estado } \\
\text { inicial }\end{array}$ & $\begin{array}{l}\text { Estado } \\
\text { final }\end{array}$ & $219+147=366$ \\
\hline
\end{tabular}

(Fonte: DANTE (2014b, p. 230).)

Perceba que no problema $\mathrm{H}$, busca-se o estado inicial cuja transformação é negativa, pois Jairo tinha uma quantidade inicial, que é o que o aluno deve descobrir, e gastou $R \$ 147,00$ obtendo um valor de $R \$ 219,00$. Para descobrir esse valor o aluno deve fazer uma adição envolvendo o valor final e a transformação ocorrida, apesar de o problema reproduzir a ideia inversa, a de decréscimo.

Já o problema I, que também se caracteriza como Transformação "busca do estado inicial", a transformação é positiva.

Quadro 9: Problema IV de Transformação.

\begin{tabular}{|c|cr|c|}
\hline Problema I & Esquema & Cálculo numérico \\
\hline $\begin{array}{l}\text { Leia, pense e resolva. } \\
\text { Nádia tinha } \mathrm{R} \$ \text { ganhou } \\
\mathrm{R} \$ 38,00 \text { e ficou com } \mathrm{R} \$ 230,00\end{array}$ & $\begin{array}{l}\text { Estado } \\
\text { inicial }\end{array}$ & $\begin{array}{l}\text { Estado } \\
\text { final }\end{array}$ & $230-38=192$ \\
\hline
\end{tabular}

(Fonte: DANTE (2014b, p. 230).)

Notamos que Nádia tinha uma quantia inicial e ganhou $R \$ 38,00$ chegando à quantia final de $\mathbf{R} \$ 230,00$. Neste caso, o aluno deve realizar uma subtração envolvendo o valor final e a transformação, apesar do problema reproduzir a ideia inversa, a de acréscimo.

Nos problemas J e K as palavras-chave "gastou" e "ganhou", induzem o aluno a associar o problema às operações de subtração e adição respectivamente, porém para essa estrutura de problema não é válida esta ideia, pois deve-se realizar a operação inversa como dito acima, caracterizando assim um raciocínio contra intuitivo.

O problema J é definido como um problema de Transformação "busca do estado intermediário". 
Quadro 10: Problema V de Transformação.

\begin{tabular}{|c|c|c|}
\hline Problema J & Esquema & Cálculo numérico \\
\hline $\begin{array}{l}\text { Leia, pense e resolva. } \\
\text { Rita tinha } R \$ 120,00 \text {, ganhou } \\
R \$ \text { e ficou com } R \$ \\
180,00 \text {. }\end{array}$ & $\begin{array}{l}120 \\
\text { Estado } \\
\text { inicial }\end{array}$ & $180-120=60$ \\
\hline
\end{tabular}

(Fonte: DANTE (2014b, p. 230).)

Neste problema, a transformação é desconhecida. Sabe-se que Rita possuía $R \$ 120,00$ e ganhou certa quantia que o aluno desconhece, sabemos também que ao final ela obteve $\mathrm{R} \$ 180,00$.

No problema K, que também é caracterizado como de Transformação cuja própria transformação é desconhecida, essa é negativa, pois Paulo possuía $R \$ 236,00$ e gastou certa quantia, obtendo ao final $R \$ 85,00$.

Quadro 11: Problema VI de Transformação.

\begin{tabular}{|c|c|c|}
\hline Problema $\mathrm{K}$ & Esquema & Cálculo numérico \\
\hline $\begin{array}{l}\text { Leia, pense e resolva. } \\
\text { Paulo tinha } \mathrm{R} \$ 236,00, \text { gastou } \\
\mathrm{R} \$ \text { e ficou em } \mathrm{R} \$ 85,00 .\end{array}$ & $\begin{array}{l}\text { Estado } \\
\text { inicial }\end{array}$ & $\begin{array}{l}\text { Estado } \\
\text { final }\end{array}$ \\
\hline
\end{tabular}

(Fonte: DANTE (2014b, p. 230).)

Notamos que o valor final obtido após a transformação é menor que o valor inicial, logo temos uma perda, diferentemente do problema anterior que trata de uma transformação positiva, pois Rita ganha uma quantia. Em ambas as resoluções a operação matemática realizada é análoga, a subtração, porém a maneira de pensar é diferente.

Assim como nos problemas de Composição, ao avançar o grau de escolaridade dos alunos, os problemas de Transformação também requerem dos estudantes um domínio mais elevado do sistema de numeração, mas a principal mudança ocorrida diz respeito a uma capacidade de interpretação maior do problema, visto que esses apresentam-se mais elaborados.

Quadro 12: Problemas VII de Transformação.

Problema L: Se Júlio der 12 figurinhas a Mário, Júlio ainda ficará com 75 figurinhas. Quantas figurinhas Júlio têm?

(Fonte: DANTE (2013a, p.137).)

Tomemos o problema $L$, no qual a ordem das informações é trazida de maneira diferente da usual, como a dos primeiros exercícios, em que são vistos primeiro os dados iniciais, em seguida a transformação e por fim o estado final. A sentença "Júlio der 12 figurinhas a Mário" remete a transformação ocorrida no problema e encontra-se no início da frase, já no meio da oração vemos a sentença "Júlio ainda ficará com 75 figurinhas" que diz respeito ao estado final do problema, no fim da frase encontramos o estado inicial, que é o procurado. 
Os Problemas de Comparação constituem uma terceira classe, na qual as situações comparam duas quantidades, uma chamada de referente e a outra de referido. O referente é o objeto no qual o problema se baseia para estabelecer uma relação, e o referido é o objeto que apresenta uma relação com o referente. Os problemas cujo referente e a relação são dados são denominados por Magina et al. (2008) como de segunda extensão. Nesse tipo de problema a criança deve partir do grupo conhecido que é o referente, e somar ou subtrair um valor, que é a relação entre os dois grupos. Quando a relação é desconhecida às autoras classificam esses problemas como de terceira extensão, há uma complexidade maior nesse caso, pois não fica explícito para a criança a operação a ser efetuada e nem os componentes da estrutura. Os problemas cujo referente é desconhecido são classificados como de quarta extensão, pois o raciocínio aditivo que o aluno deve desenvolver é mais sofisticado do que os outros grupos de problemas, e este só será apropriado pelo aluno se o professor possibilitar a resolução dessas tarefas. No entanto, essa estrutura não foi encontrada nas obras analisadas.

No problema M é dado o valor do referente, superfície ocupada pelos continentes, e do referido, que se trata do valor da superfície ocupada pelos rios, mares e lagos. Neste caso apresentado, a relação entre as medidas é desconhecida, para resolver esse problema o aluno deverá encontrar a diferença entre as duas medidas.

Quadro 134: Problema I de Comparação.

\begin{tabular}{|c|c|c|c|}
\hline Problema M & & Esquema & Cálculo numérico \\
\hline $\begin{array}{l}\text { O planeta Terra tem cerca de } \\
150000000 \text { de quilômetros } \\
\text { quadrados ( ) de superfície } \\
\text { ocupados pelos continentes e } \\
360000000 \text { de quilômetros } \\
\text { quadrados ( ) ocupados pelos } \\
\text { mares, oceanos, rios e lagos. } \\
\text { Responda: } \\
\text { a) Na superfície do planeta há } \\
\text { mais terra ou mais água? } \\
\text { b) Quanto a mais? }\end{array}$ & 360000000 & Referente & $\begin{array}{c}360.000 .000 \\
-150.000 .000 \\
210.000 .000\end{array}$ \\
\hline
\end{tabular}

(Fonte: DANTE (2013b, p. 65).)

Já no problema $\mathrm{N}$ a relação entre as medidas é conhecida " $\mathrm{R} \$ 4,00$ a menos" assim como o referente "Lucas tem R\$ 742,00".

Quadro 54: Problema II de Comparação.

\begin{tabular}{|c|c|}
\hline Esquema & Cálculo numérico \\
\hline$?$ & \\
\hline
\end{tabular}

(Fonte: DANTE (2013b, p. 66).) 
O exercício deseja que o aluno encontre o referido, a quantidade de dinheiro que Pedro tem em relação a Lucas. Para isso o aluno deve subtrair a relação do valor referente.

Nos problemas $\mathrm{M}$ e $\mathrm{N}$ as relações são respectivamente positivas e negativas, pois no primeiro caso o problema deixa explícito quando utiliza a expressão "a mais". Já no segundo exemplo, Pedro tem $\mathrm{R} \$ 4,00$ a "menos do que" Lucas, logo subintende-se que a classificação é negativa.

Até agora apresentamos problemas com apenas um único raciocínio aditivo, mas existem aqueles que envolvem dois ou mais raciocínios aditivos simultaneamente, classificados por Magina et al. (2008) como Problemas Mistos. Nessa classe cabem os problemas de Composição de Transformações, Transformação de Composição e Comparação com Composição de Transformação. Os livros analisados apresentaram somente o problema de Composição de Transformação.

No problema $O$ temos um problema de Composição de Transformação, o estado inicial é o valor do saldo bancário do Sr. Vítor no início da semana de $\mathrm{R} \$ 500,00$ as duas transformações ocorridas foram, uma positiva (depósito de $R \$ 200,00$ ) e a outra negativa (retirada de $R \$ 300,00$ ), o estado final é o saldo do Sr. Vítor no final da semana.

Quadro 15: Problema I de Composição de Transformação.

\begin{tabular}{|l|l|l|}
\hline \multicolumn{1}{|c|}{ Problema O } & Cálculo numérico \\
\hline $\begin{array}{l}\text { No início da semana, o saldo } \\
\text { bancário do Sr. Vítor era de } \\
\mathrm{R} \$ 500,00 . \text { Durante a semana } \\
\text { ele fez um depósito de } \mathrm{R} \$ \\
\text { 200,00 e uma retirada de } \mathrm{R} \\
\text { 300,00. Qual foi o saldo dele } \\
\text { no final da semana? }\end{array}$
\end{tabular}

(Fonte: DANTE (2013b, p. 66).)

Para descobrir esse valor, o aluno deverá realizar primeiramente uma adição no valor inicial e em seguida uma subtração no valor obtido após a operação de adição, chegando assim ao saldo final.

Nem todos os problemas apresentam o estado inicial e final. Alguns deles fornecem apenas o valor das transformações ocorridas para que o aluno descubra quanto foi "gasto" ou "ganho" ou ainda qual dos dois prevalece. Quando ambos acontecem em um mesmo problema, muitas vezes o estado inicial e o estado final não são explorados. Estudantes dos Anos Iniciais terão de analisar de maneira geral para descobrir se houve ganho ou perda e qual seria esse valor. Isto pode ser um elemento que dificulta a resolução, pois muitos alunos consideram o problema como impossível (MAGINA et al., 2008). Problemas como esses auxiliam os alunos a construírem ideias que envolvam o conceito de adição com números inteiros. 
Como não houve a presença de três classes de problemas apresentadas por Magina et al. nas coleções analisadas, vamos apresentar exemplos dessas estruturas criados por nós inspiradas na autora. Esses problemas são das seguintes estruturas: Comparação com Composição de Transformação (problema P), Transformação de Composição (problema Q), classificados como Problemas Mistos, e Comparação "busca pelo referente" (problema R) que envolve apenas um raciocínio.

Os problemas de Comparação com Composição de Transformação envolvem tanto Transformação quanto Composição. O aluno deve realizar a operação relacionada à estrutura de Transformação e de posse desse resultado, realizar a operação ligada à estrutura de Composição. Esses problemas possuem uma complexidade maior do que os outros problemas mistos e é dentre todos o mais extenso, para facilitar a resolução deste problema, o aluno deve construir um diagrama que auxilie a organização dos dados do enunciado (MAGINA et al., 2008).

Quadro 16: Problema I de Comparação com Composição de Transformação.

\begin{tabular}{|l|l|l|l|}
\hline \multicolumn{1}{|c|}{ Problema P } & Cálculo numérico \\
\hline $\begin{array}{l}\text { Fátima, Victor e Tiago jogaram o } \\
\text { jogo da memória. Para cada } \\
\text { resposta certa, eles ganhavam uma } \\
\text { ficha, que equivalia a um ponto. }\end{array}$ \\
$\begin{array}{l}\text { Fátima, entrou no jogo com 15 } \\
\text { fichas, Victor entrou com 2 fichas a } \\
\text { mais do que Fátima e Tiago com } 5 \\
\text { fichas a menos do que Victor. No } \\
\text { jogo Fátima ganhou o mesmo } \\
\text { tanto de fichas que Victor tinha ao } \\
\text { entrar no jogo. Victor ganhou 5 } \\
\text { fichas no jogo, já Tiago acertou } \\
\text { algumas adivinhações e no final do } \\
\text { jogo tinha o mesmo tanto de fichas } \\
\text { que Fátima tinha quando ela } \\
\text { entrou no jogo. Perguntas: } \\
\text { Quantas fichas tinha Victor quando } \\
\text { ele entrou no jogo? Quantas fichas } \\
\text { Tiago perdeu? Com quantas fichas } \\
\text { Fátima terminou o jogo? Com } \\
\text { quantas fichas Victor terminou o } \\
\text { jogo? }\end{array}$
\end{tabular}

(Fonte: Elaborado pelos autores, inspirado em Magina et al. (2008, p. 56).)

Nesse problema as únicas informações explícitas são: quantidade de fichas de Fátima e a quantidade de fichas que Victor ganhou no jogo. Para resolver as duas primeiras questões temos que realizar comparações, obtendo os estados iniciais de todos os três jogadores. De posse desses valores temos condições para resolver as três últimas questões, que envolvem transformações.

O problema Q é classificado como de Transformação de Composição, temos aqui um problema que trata tanto de transformação quanto composição. Para tal podemos iniciar a resolução do problema calculando as transformações ocorridas. 
De posse desses resultados, podemos juntar as duas partes para obter o todo, ou seja, realizar a composição exigida.

Quadro 17: Problema I de Transformação de Composição.

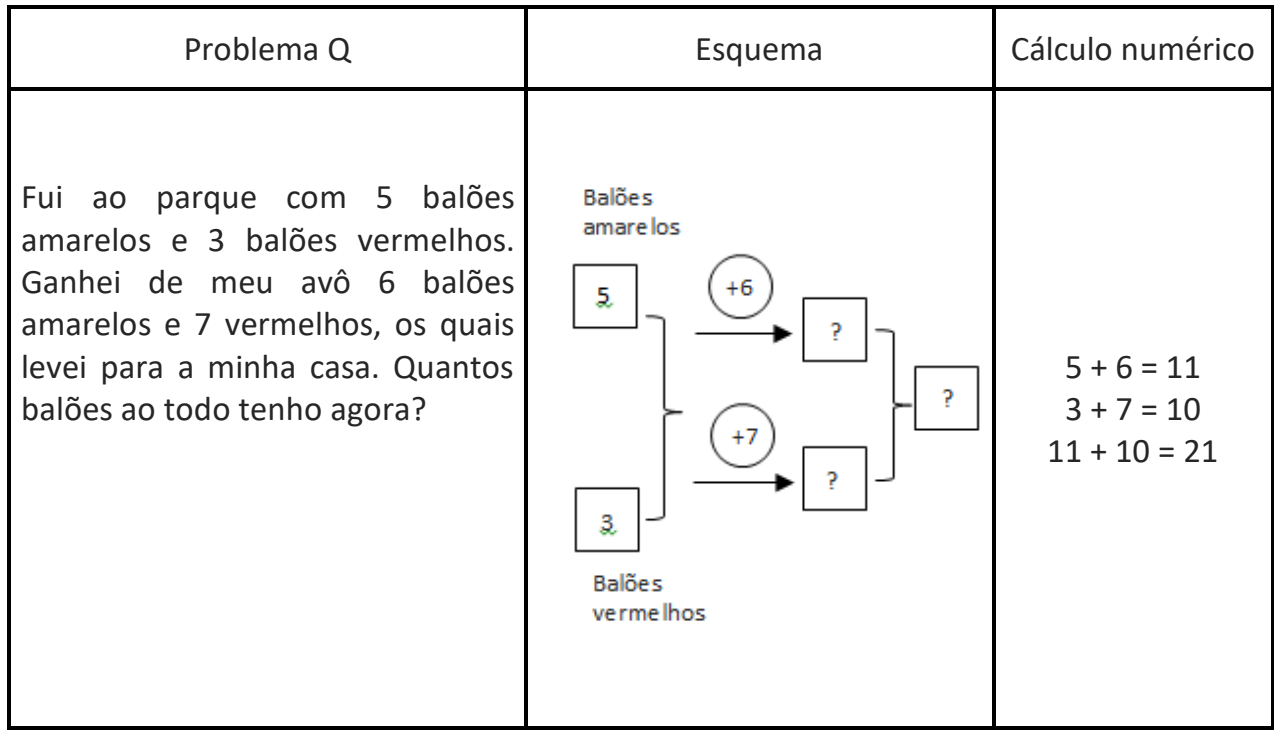

(Fonte: Elaborado pelos autores, inspirado em Magina et al. (2008, p. 55).)

A classe de situações de comparação, em que se pretende encontrar o referente (problema $\mathrm{R}$ ) é considerada difícil, pois pensamos sobre o referente para encontrar o referido e nessa situação é justamente o contrário.

Quadro 18: Problema I de Comparação "busca do valor do referente".

\begin{tabular}{|l|l|r|}
\hline Problema R & Esquema & Cálculo numérico \\
\hline $\begin{array}{l}\text { Pedro tem alguns carrinhos e } \\
\text { Ricardo tem 50. Se Ricardo tem 15 } \\
\text { carrinhos a mais que Pedro, } \\
\text { quantos carrinhos tem Pedro? }\end{array}$ & Reforente & Relação \\
\hline
\end{tabular}

(Fonte: Elaborado pelos autores, inspirado em Magina et al. (2008, p. 49).)

Note que Pedro é o referente, porque o valor de Ricardo está descrito a partir do valor de Pedro em termos de quantos a mais, uma comparação positiva, Pedro tem em ralação ao tanto que Ricardo tem, o não ter de onde partir dificulta para a criança o raciocínio do problema. Se ao invés de " 15 carrinhos a mais que Pedro" tivéssemos a sentença " 15 carrinhos a menos que Pedro" seria um exemplo de uma situação de comparação negativa.

\section{DADOS QUANTITATIVOS}

A análise de todos os problemas presentes na coleção analisada englobou mil e oitenta e cinco (1085) problemas presentes nos cinco (05) volumes da coleção de Luiz Roberto Dante - PNLD 2013, sendo cento e vinte e sete (127) do primeiro ano, duzentos e seis (206) do segundo ano, duzentos e vinte e sete (227) do 
terceiro ano, duzentos e noventa e um (291) do quarto ano e duzentos e trinta e quatro (234) do quinto ano. Considerando a análise realizada, os tipos de problemas conforme a classificação de Magina et al. (2008), disponibilizamos os dados no quadro 19 , indicando para cada tipo de estrutura a quantidade de problemas presentes em cada um dos volumes da coleção analisada.

Quadro 19: Quantificação e clarificação dos problemas analisados.

\begin{tabular}{|c|c|c|c|c|c|c|}
\hline ESTRUTURAS & $\begin{array}{l}\text { 10 } \\
\text { ANO }\end{array}$ & $\begin{array}{l}20 \\
\text { ANO }\end{array}$ & $\begin{array}{l}\text { 3o } \\
\text { ANO }\end{array}$ & $\begin{array}{l}\text { 40 } \\
\text { ANO }\end{array}$ & $\begin{array}{l}\text { 5o } \\
\text { ANO }\end{array}$ & TOTAL \\
\hline Composição (busca pelo todo) & 57 & 86 & 112 & 109 & 102 & 466 \\
\hline Composição (busca pela parte) & 12 & 6 & 6 & 21 & 39 & 84 \\
\hline $\begin{array}{l}\text { Transformação (Transformação positiva - } \\
\text { Busca do Estado Final) }\end{array}$ & 15 & 21 & 20 & 27 & 10 & 93 \\
\hline $\begin{array}{c}\text { Transformação (Transformação positiva - } \\
\text { Busca do Estado Intermediário) }\end{array}$ & 1 & 1 & 4 & 13 & 9 & 28 \\
\hline $\begin{array}{c}\text { Transformação (Transformação positiva - } \\
\text { Busca do Estado Inicial) }\end{array}$ & 0 & 1 & 3 & 12 & 3 & 19 \\
\hline $\begin{array}{c}\text { Transformação (Transformação negativa - } \\
\text { Busca do Estado Final) }\end{array}$ & 20 & 23 & 26 & 25 & 20 & 114 \\
\hline $\begin{array}{c}\text { Transformação (Transformação negativa - } \\
\text { Busca do Estado Intermediário) }\end{array}$ & 2 & 3 & 3 & 7 & 2 & 17 \\
\hline $\begin{array}{c}\text { Transformação (Transformação negativa - } \\
\text { Busca do Estado Inicial) }\end{array}$ & 0 & 2 & 4 & 4 & 2 & 12 \\
\hline $\begin{array}{c}\text { Comparação (Positiva - Busca do valor } \\
\text { referido) }\end{array}$ & 1 & 3 & 3 & 3 & 1 & 11 \\
\hline $\begin{array}{c}\text { Comparação (Negativa - Busca do valor } \\
\text { referido) }\end{array}$ & 2 & 5 & 2 & 3 & 1 & 13 \\
\hline $\begin{array}{c}\text { Comparação (Busca da relação entre as } \\
\text { medidas) }\end{array}$ & 15 & 50 & 40 & 52 & 40 & 197 \\
\hline Composição de Transformação & 2 & 5 & 4 & 15 & 5 & 31 \\
\hline Total & 127 & 206 & 227 & 291 & 234 & 1085 \\
\hline
\end{tabular}

(Fonte: Autores da pesquisa.)

De acordo com nossas análises, a estrutura que predomina em todos os livros é a de Composição "busca pelo todo", aparecendo em cinquenta e sete (57) problemas no livro do primeiro ano, oitenta e seis (86) no segundo ano, cento e doze (112) no terceiro, cento e nove (109) no quarto e cento e dois (102) no quinto ano. Ao total, quatrocentos e sessenta e seis (466) problemas foram classificados como Composição "busca pelo todo". Acreditamos que essa predominância se justifique pelo fato da ideia dessa estrutura ser a presente nas primeiras situações que a criança se depara, e sua solução estar associada ao processo de contagem. Em contrapartida, as estruturas que menos se fizeram presentes foram as de 
Comparação "Positiva - Busca do valor referido", Transformação "Negativa - Busca do Estado Inicial" e Comparação "Negativa - Busca do valor referido", aparecendo onze (11), doze (12) e treze (13) vezes, respectivamente.

Percebemos que os problemas de Transformação "busca do estado inicial", tanto positiva quanto negativa não foram identificados no livro do primeiro ano. Segundo Magina et al. (2008) isso ocorre pelo fato que esta estrutura é classificada como um problema de quarta extensão, exigindo do aluno um maior domínio do conceito de adição, que ainda não encontra-se formulado para essa faixa etária.

Os problemas de Comparação com Composição de Transformação, Transformação de Composição e Comparação busca pelo referente não foram identificados em nenhum dos volumes analisados. Isso possivelmente ocorre por se tratar de problemas com grau de dificuldade maior para resolução, exigindo do aluno um raciocínio matemático mais elaborado do que se espera para os Anos Iniciais (MAGINA et al., 2001), em outras palavras, alguns desses problemas podem não "viver" neste nível de escolaridade.

Outro resultado que vale a pena se discutir é que ao analisar o manual do professor, encontramos indícios de que a Teoria dos Campos Conceituais, mais especificamente o Campo Conceitual Aditivo, foi tomada como referência na elaboração dos problemas destes livros, ou seja, trata-se de um indício de como o Autor da coleção deseja que os alunos resolvam as atividades presentes nos livros, o que recai sobre as ideias de Contrato Didático (Brousseau; 1986): o aluno busca, na ação do professor ou no livro didático, encontrar algum sinal do que é esperado que ele faça. Tais evidências encontram-se nos diagramas conforme proposto por Vergnaud, para os problemas do Campo Conceitual Aditivo. A figura 1 evidencia o caso retratado acima.

Figura 1: Identificação de indícios das estruturas na resolução do professor, grifos nossos.

3) Problemas

Pense, resolva as situações e responda em seu caderno:

a) Pensei em um número, somei 25 a ele e obtive 81 . Em que número oensei?

b) Tinha uma quantia, gastei $R \$ 147,00$ e fiquei com $R \$ 209,00$. Cue quantia eu tinha? as $356,00 \stackrel{-147}{\longrightarrow}(209)+147$

c) Na quitanda de dona Marta havia 1200 laranjas no início do dia e 139 laranjas no fim do dia. Quantas laranjas foram vendidas nesse dia? $106 t$

d) A projeção de um filme começou às $14 \mathrm{~h} 18 \mathrm{~min}$ e terminou às $15 \mathrm{~h} 45 \mathrm{~min}$. Qual foi a duração do filme? th 27 min $15-14=1 ;, 45-18=27$

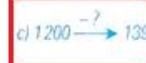

(Fonte: DANTE (2013b, p. 67).)

\section{CONSIDERAÇÕES FINAIS}

Decorrente das análises dessa pesquisa, pudemos perceber indicativos da Teoria dos Campos Conceituais sendo transposta para a prática no cotidiano da sala de aula a partir do livro didático, principal ferramenta de ensino do professor, conforme exemplificado por meio da figura 1. 
Considerando a quantidade de problemas analisados (1085), chegamos a algumas considerações que nos ajudam a responder nosso problema de pesquisa: Com que frequência, e em qual ano escolar, os problemas de cada classe do Campo Conceitual Aditivo são abordados nas obras analisadas? A primeira delas é que, apesar de nem todas as estruturas do Campo Conceitual Aditivo terem sido encontradas nos livros didáticos, a maioria das que possuem um único raciocínio envolvido foram identificadas. As exceções se atêm as estruturas de Transformação "busca do Estado Inicial", não encontrada no livro do primeiro ano, e a estrutura de Comparação "busca do valor referente", a única não encontrada em nenhuma obra. Quanto aos próprios Problemas Mistos, duas das estruturas desse tipo não foram identificadas porque eles certamente envolvem um raciocínio mais sofisticado que não condiz com o desenvolvimento dos alunos no início das séries iniciais. Apesar disso, acreditamos que cabe ao professor trabalhar ou não com problemas desse formato, tendo em vista um diagnóstico da sua turma, visando avançar os conhecimentos dos alunos em relação ao processo de aprendizagem, e expandindo seus conhecimentos para situações mais elaboradas.

Outro fato importante é que as estruturas aditivas não se atêm apenas a problemas do capítulo de adição e subtração, elas permanecem sendo usadas mescladas ao estudo de outros conceitos, isso fica claro quando encontramos problemas que envolvem a adição em capítulos de multiplicação, divisão, formas geométricas etc. Essa diversificação nas situações problemas contribui diretamente com o processo de compreensão do conceito, segundo Vergnaud (1993).

Acreditamos que essa diversificação nas situações viabiliza que o aluno possa se desprender do algoritmo do cálculo e desenvolver o raciocínio implícito nos problemas do Campo Aditivo. Assim, ele passa a não apenas designar a resolução de um problema olhando para possíveis palavras-chave do enunciado, que podem induzi-lo ao erro ou a decorar o algoritmo da soma e subtração pegando valores evidentes no problema, mas sim compreender o porquê de realizar uma determinada operação para resolução da situação problema.

Pensando nisso, a compreensão e sistematização do conceito de adição pelo aluno refletirão futuramente no estudo de outros conceitos matemáticos, visto que estes se encontram atrelados e interligados uns aos outros, como a própria teoria dos campos conceituais enuncia. Ademais, ressaltamos a importância do papel do professor como mediador do conhecimento, pois com as escolhas adotadas pelo docente o aluno poderá chegar a um conhecimento verdadeiro que é adquirido com a familiarização e a prática.

Em consonância com Magina et al. (2008), acreditamos que quando o professor compreende a maneira como o aluno toma posse de um conceito, passa a estar mais instrumentalizado para introduzi-lo e desenvolvê-lo em sala de aula. Consequentemente, haverá uma melhoria na prática docente que acarreta em um melhor desempenho do aluno ao realizar suas tarefas. Por fim, cabe pontuar a importância de estudos desse formato, focados na análise de livros didáticos, por contribuir para a compreensão e reflexão da educação em nosso país. 


\title{
Addition and subtraction problems in textbooks of mathematic in basic education: an analysis under the aspects of the theory of conceptual fields
}

\begin{abstract}
The Theory of Conceptual Fields provides us with reflections about the structures and classes of addition and subtraction problems, which are present in the Additive Conceptual Field. This work, we aimed to investigate and discuss the problems from this Conceptual Field, present in a collection of textbooks, directed towards the initial years of Basic Education. Each structure found in the books was discussed presenting its format, as well as an example of this one that is present in the textbooks, accompanied by reflections. Our analysis covered a thousand and eighty-five (1085) exercises of the five (05) volumes of the Ápis collection, which allowed us to reach quantitative and qualitative conclusions, among which we highlight the classes of problems prevalent in each book, the different types of problems present in the different volumes, as the school years advance.
\end{abstract}

KEYWORDS: Additive conceptual field. Mathematics teaching. Textbook. 


\section{REFERÊNCIAS}

ANJOS, D. R. K. Uma análise praxeológica das operações de adição e subtração de números naturais em uma coleção de livros didáticos dos anos iniciais do Ensino Fundamental. 2014. 142f. Dissertação (Ed. Matemática), UFMS, Campo Grande, 2014.

BATISTA, C. G. Fracasso Escolar: análise de erros em operações matemáticas. Zetetikè. Ano 3, n.4, p. 61-72, 1995.

BITTAR, M. A Teoria Antropológica do Didático como ferramenta metodológica para análise de livros didáticos. Zetetikè. Campinas, SP, v.25, n. 3, set./dez.2017, p.364-387.

BRASIL. Ministério da Educação. Secretaria de Educação. Parâmetros Curriculares Nacionais: Matemática. Brasília, 1998.

BROUSSEAU, G. Introdução ao estudo da teoria das situações didáticas: conteúdos e métodos de ensino. São Paulo: Ática, 2008.

BROUSSEAU, G. (1986). Fondements et méthodes de la Didactique des Mathématiques. Recherches en Didactique des Mathématiques, 7(2), 33-115.

DANTE, L.R. Ápis Alfabetização Matemática - 30 ano. São Paulo: Editora Ática, 2014b.

DANTE, L.R. Ápis Alfabetização Matemática - 1ำ ano. São Paulo: Editora Ática, 2014a. Impresso.

DANTE, L.R. Ápis Matemática - 5o ano. São Paulo: Editora Ática, 2013b.

DANTE, L.R. Ápis Matemática - 40 ano. São Paulo: Editora Ática, 2013a.

DANTE, L.R. Ápis Alfabetização Matemática - 20 ano. São Paulo: Editora Ática, 2012.

MAGINA, S. et al. Repensando a Adição e a Subtração: contribuições da Teoria dos Campos Conceituais. PROEM, São Paulo, 2008. 
REZENDE, V.; BORGES, F. Futuros Professores de Matemática nos Anos Iniciais e suas Estratégias Diante de Problemas do Campo Conceitual Aditivo. Educação Matemática Pesquisa. São Paulo, Vol. 17, p. 327 - 352, 2015.

SANTANA, E.R.S. Adição e subtração: o suporte didático influencia a aprendizagem do estudante? Ilhéus. BA: Editus, 2012.

VERGNAUD, G. A criança, a matemática e a realidade. 3. ed. Curitiba: UFPR, 2009.

VERGNAUD, G. A trama dos campos conceituais na construção dos conhecimentos. Revista do GEMPA, Porto Alegre: Ed. GEMPA, n. 4, p. 9-19, 1996.

VERgnAUD, G. Teoria dos Campos Conceituais. Anais do 10 Seminário Internacional de Educação Matemática do Rio de Janeiro. Rio de Janeiro, 1993, p.1-16.

VERGNAUD, G. La théorie des champs conceptuels. Recherche en Didactique des Mathématiques. Grenoble: La Pensée Sauvage, vol. 10, n. 2.3, p. 133 a 170 1990.

VERGNAUD, G. Multiplicative structures. In Lesh, R. and Landau, M. (Eds.) Acquisition of Mathematics Concepts and Processes. New York: Academic Press Inc, 1983, p. 127-174. 
Recebido: 2018-04-23

Aprovado: 2019-02-25

DOI: $10.3895 /$ rbect.v12n2.8189

Como citar: REZENDE, V.; ANTUNES, V. H. R. B.; AGUIAR, F. J.; PEREIRA, T. Problemas de adição e subtração nos livros didáticos de matemática dos anos iniciais: uma análise à luz da teoria dos campos conceituais. Revista Brasileira de Ensino de Ciência e Tecnologia, v. 12, n. 2, 2019. Disponível em:

<https://periodicos.utfpr.edu.br/rbect/article/view/8189>. Acesso em: xxx.

Correspondência: Veridiana Rezende - rezendeveridiana@gmail.com

Direito autoral: Este artigo está licenciado sob os termos da Licença Creative Commons-Atribuição 4.0 Internacional. 